\title{
Disease Severity Estimates-Effects of Rater Accuracy and Assessment Methods for Comparing Treatments
}

\author{
C. H. Bock, United States Department of Agriculture-Agricultural Research Service SEFTNRL, Byron, GA 31008; M. El Jarroudi, \\ Université de Liège, Department of Environmental Sciences and Management, 6700 Arlon, Belgium; L. A. Kouadio, Agriculture and \\ Agri-Food Canada Lethbridge Research Centre, Lethbridge, Alberta, T1J 4B1 Canada; C. Mackels, Université de Liège, Department of En- \\ vironmental Sciences and Management; K.-S. Chiang, Division of Biometrics, Department of Agronomy, National Chung Hsing University, \\ Taichung, Taiwan, 402; and P. Delfosse, Centre de Recherche Public-Gabriel Lippmann, Environment and Agro-Biotechnologies Department, \\ 4422 Belvaux, Luxembourg
}

\begin{abstract}
Bock, C. H., El Jarroudi, M., Kouadio, L. A., Mackels, C., Chiang, K.-S., and Delfosse, P. 2015. Disease severity estimates-Effects of rater accuracy and assessment methods for comparing treatments. Plant Dis. 99:1104-1112.

Assessment of disease severity is required for several purposes in plant pathology; most often, the estimates are made visually. It is established that visual estimates can be inaccurate and unreliable. The ramifications of biased or imprecise estimates by raters have not been fully explored using empirical data, partly because of the logistical difficulties involved in different raters assessing the same leaves for which actual disease has been measured in a replicated experiment with multiple treatments. In this study, nearest percent estimates (NPEs) of Septoria leaf blotch (SLB) on leaves of winter wheat from nontreated and fungicide-treated plots were assessed in both 2006 and 2007 by four raters and compared with assumed actual values measured using image analysis. Lin's concordance correlation $\left(\mathrm{LCC}, \rho_{c}\right.$ ) was used to assess agreement between the two approaches. NPEs were converted to Horsfall-Barratt (HB) midpoints and were compared with actual values. The estimates of SLB severity from fungicide-treated and nontreated plots were analyzed using generalized linear mixed modeling to ascertain effects of rater using both the NPE and HB values. Rater 1 showed good accuracy $\left(\rho_{c}=0.986\right.$ to $0.999)$, while raters 3 and 4 were less accurate ( $\rho_{c}=0.205$ to 0.936$)$. Conversion to the $\mathrm{HB}$ scale had little effect on bias but reduced numerically

both precision and accuracy for most raters on most assessment dates (precision, $r=-0.001$ to -0.132 ; and accuracy, $\rho_{c}=-0.003$ to -0.468 ) Interrater reliability was also reduced slightly by conversion of estimates to HB midpoint values. Estimates of mean SLB severity were significantly different between image analysis and raters 2,3 , and 4 , and there were frequently significant differences among raters $(F=151$ to $1,260, P=0.001$ to $P<0.0001)$. Only on 26 June 2007 did conversion to the HB scale change the means separation ranking of rater estimates. Nonetheless, image analysis and all raters were able to differentiate control and treated-plot treatments $(F=116$ to $1,952, P=0.002$ to $P<0.0001$, depending on date and rater). Conversion of NPEs to the HB scale tended to reduce $F$ values slightly (2006: NPEs, $F=116$ to $276, P=0.002$ to 0.0005 ; and, for the HB-converted values, $F=101$ to $270, P=0.002$ to $0.0005 ; 2007$ : NPEs, $F=164$ to $1,952, P=0.001$ to $P<0.0001$; and, for HB-converted values, $F=126$ to $1,633, P=0.002$ to $P<0.0001)$. The results reaffirm the need for accurate and reliable disease assessment to minimize over- or underestimates compared with actual disease, and the data we present support the view that, where multiple raters are deployed, they should be assigned in a manner to reduce any potential effect of rater differences on the analysis
\end{abstract}

Estimating or measuring the severity of disease on plants is fundamental to many studies in plant pathology and has practical applications where disease control is needed, including crop disease surveys, decision making, comparing crop management approaches, understanding and estimating yield loss, and rating germplasm for crop breeding purposes $(2,6,8,11,15,20,22,32,33)$. Numerous reports in the literature describe the different methods of plant disease assessment $(6,15,30,33,39)$. However, the method that is most widely used to assess plant disease severity is visual assessment, whereby a rater or raters visually estimate the percent area diseased on a leaf or other plant organ (6). Visual assessment can be nondestructive, and is often the least expensive, fastest, and most practical option for assessing plant disease.

There are issues with visual assessment. Several studies over the last 30 years have demonstrated that visual estimates can be inaccurate and unreliable $(1,5,16,17,27-29,31,34,35,40,46)$. Accuracy in measurement science can be defined as the closeness of estimated values to the actual value, and reliability is the extent to which the same estimate obtained under different conditions yields similar results (27,36). Apart from rater subjectivity $(5,31,34)$, use of various category scales in

Corresponding author: C. H. Bock; E-mail address: clive.bock@ars.usda.gov Accepted for publication 30 November 2014.

http://dx.doi.org/10.1094/PDIS-09-14-0925-RE

This article is in the public domain and not copyrightable. It may be freely reprinted with customary crediting of the source. The American Phytopathological Society, 2015. assessment of disease severity, such as the Horsfall and Barratt scale (17), might further lead to erroneous results $(3,7,9,32)$. The bias and lack of precision in estimates of disease has the potential to result in type II errors, where the null hypothesis $\left(\mathrm{H}_{0}\right)$ fails to be rejected when $\mathrm{H}_{0}$ is false. Type II errors have been reported where different methods have been used to assess disease $(3,9,44)$, with discrepancies in means separation ranking observed $(10,38,44)$. However, in one study comparing actual diseased areas (measured using image analysis) to estimates based on visual assessments using the 0 -to- $100 \%$ ratio scale, there were no difference in the conclusions drawn (42). The raters in that study assessed the percentage of diseased area of the flag leaf over the whole plot, whereas image analysis was performed on 10 flag leaves collected from each plot, precluding a direct comparison of estimates.

For symptoms of many plant diseases, image analysis is often used to measure the actual values against which accuracy of visual estimates by raters are compared $(5,25,28,29,35,38,41,42)$. Where multiple raters assess plots in the same experiment and interrater reliability is high, the assessments by different raters will be similar (31); however, some raters may have bias (which can lead to a discrepancy in accuracy of the mean), which also leads to lower interrater reliability $(31,34,35,38,46)$. The resulting data might end up with excessive variance or rater biases adding to (or detracting from) treatment differences, resulting in potentially incorrect conclusions being drawn from the analysis.

The ramifications of biased or imprecise disease estimates by different raters or methods have not been fully explored using empirical data, partly because of the logistical difficulties involved in different raters assessing the same leaves for which actual disease has been measured in a replicated experiment with multiple treatments $(38,43)$, 
although this has been done to some degree to explore the use of disease scales using actual data or simulations $(3,9,10,44)$. In this study, we describe an experiment comparing different visual rater estimates (called nearest percent estimates [NPEs]) with actual values using image analysis applied to the Zymoseptoria graminicola (cause of Septoria leaf blotch [SLB] of winter wheat) pathosystem. The aim was to characterize rater bias and imprecision and their effects on the estimates of mean severity on leaves of plants from fungicide-treated and nontreated control plots, and the effect of these rater characteristics on the outcome of analyses of treatment effects. In addition, we converted the rater NPEs to the Horsfall-Barratt (HB) scale, and explored the effects of using categorybased data.

The specific objectives were to (i) assess bias and precision of severity estimates by raters with distinct ability or experience, (ii) characterize the effect of converting the NPEs to the HB scale both on bias and precision, and (iii) assess the effect of different raters and assessment methods for comparing treatment means.

\section{Materials and Methods}

Experiment location and treatments. Leaves for assessment were obtained from field experiments located at Everlange $\left(49^{\circ} 46^{\prime} \mathrm{N}\right.$, $5^{\circ} 57^{\prime} \mathrm{E}$ ), in the Grand Duchy of Luxembourg, in the 2005-06 and 2006-07 cropping seasons. Winter wheat 'Achat' was sown on 10 October in 2005 and 2006. Plot size was $12 \mathrm{~m}^{2}$, with a randomized complete block design and four replicates of two treatments (fungicide treated and nontreated control). Management practices are indicated in Table 1 and as previously detailed (13).

Visual estimates of disease severity. Visual estimates (NPEs) of SLB and associated senescence were made on the flag leaf (F1) and the two leaves below the flag leaf (F2 and F3) on five wheat stems per plot (with a total of 20 plants assessed at growth stage 73 to 77 [47] on 21 June and 4 July 2006 and 19 and 26 June 2007). On 26 June 2007 , only F1 was assessed. The estimates of SLB severity on each leaf were made by four raters. On each assessment date, for each treatment-rater combination, sample size was $n=60$ leaves (except on 26 June 2007, when sample size $n=20$ ). Rater 1 was a trained plant pathologist. Prior to making the assessments, the other three raters were trained in the symptoms of SLB and severity estimation using existing standard area diagrams (SADs) for SLB (18), and by completing computer-based disease assessment training (45). Rater 2 had some experience of disease severity monitoring but raters 3 and 4 were novices in disease severity estimation in 2006. Subsequent to estimation, each estimate of severity was converted to the equivalent HB scale category before being converted to the midpoint value for statistical analysis and comparison with the NPEs $(3,17,31)$. Although category scale data such as HB scale data can be analyzed directly using either nonparametric of parametric methods (27), the midpoint conversion method has been widely used and, in this case, allows a direct comparison between the two scales (27).

Digital image processing. The same leaves used for the visual assessments (F1, F2, and F3) were digitized using a digital camera (Canon Powershot A620; Canon Inc.) at a distance of $40 \mathrm{~cm}$, perpendicular to the leaf. The Canon Powershot A620 camera takes images of 7.1 megapixels, which has been demonstrated as ample resolution for the purpose of image analysis (42). The leaves were imaged in a nondestructive manner by gently attaching the leaf blade with removable double-sided tape (Scotch 666) to a blue background equipped with a handheld support for the camera. Care was taken not to curl or deform the leaves of the plant, which were gently pressed flat to the blue support background. For each leaf, the area with symptoms of SLB and associated senescence was measured using HSI color space in the image analysis software Assess V2.0 (23). The determination of the leaf area was facilitated by the use of the blue background, and Assess allows the use of macros to automate the analysis of all the images in an efficient, standardized way. SLB appears as light-brown to reddish-brown irregular lesions, containing small brown or black pycnidia. The margin between green, healthy leaf and visibly diseased or senescent leaf area was easily differentiated in Assess, and the operator based the separation of the two areas on this margin.

Data analysis. All analyses were done in SAS (v9.3; SAS Institute, Cary, NC) or MS Excel (Microsoft, Redmond, WA). First, agreement between rater estimates (and their HB-converted values; 3 ) and the actual values of disease severity for each of the control and treated plots on each date was analyzed using Lin's concordance correlation (LCC). LCC measures the closeness of the rater estimates to the actual values and is commonly used to judge agreement in plant disease severity assessments $(5,7,24,27,31)$. LCC analysis generates several parameters, including a measure of constant bias $(\mu)$, systematic bias $(v)$, generalized bias $\left(C_{b}\right)$, and accuracy $\left(\rho_{\mathrm{c}}\right.$, called LCC coefficient [LCCC]), which is the product of generalized bias and precision, measured by the correlation coefficient $(r)$. Thus, systematic bias occurs when the slope of the best fitting line $\neq 1$, and constant bias when the intercept of the best fitting line $\neq 0$. The calculations were made as described previously (31). When there is perfect concordance between the estimates and the actual values, systematic bias (scale shift, $v$ ) $=1$, constant bias (location shift, $\mu)=0$, generalized bias $\left(C_{b}\right)=1$, precision $(r)=1$, and accuracy $\left(\rho_{c}\right)=1$. Any deviation from these values indicates loss of precision or accuracy.

Interrater reliability for the original and $\mathrm{HB}$-converted data were analyzed using pairwise linear regression (proc reg) of the estimates by all four raters, calculating the coefficient of determination $\left(R^{2}\right)$. To compare variability of these data, the coefficient of variation $(\mathrm{CV})$ was calculated for each of the regression solutions (the $\mathrm{CV}$ is defined as $100 \times$ root mean square error/mean of the response variable, and is a dimensionless parameter that allows comparison of variation of the populations). The intraclass correlation coefficient (ICC; $\rho$ ) was calculated for each treatment on each assessment date. The ICC compares between-subject and within-subject variance; both the ICC and its confidence limits were calculated using a SAS macro (26), and were used as the basis to compare methods.

A generalized linear mixed model (proc glimmix) was used to analyze for overall effects of leaf layer (F1, F2, and F3), treatment (control and fungicide treated), and rater (image analysis and raters 1 to 4) on each date for both the rater NPE data and HB-converted values. Fixed effects included rater, treatment, and leaf layer, with random

Table 1. Agronomic details and fungicide treatments applied to winter wheat Achat in 2006 and 2007 at Everlange, Grand Duchy of Luxembourg

\begin{tabular}{|c|c|c|c|c|c|c|}
\hline Year & Previous crop & Treatment & GS of application $y$ & Fungicide $^{\mathrm{z}}$ & Date of application & Nitrogen $(\mathrm{kg} / \mathrm{ha})$ \\
\hline \multirow[t]{4}{*}{2006} & Fallow & Control & $\ldots$ & No fungicide application & & 225 \\
\hline & & Treated & GS31 & 0.7 liter/ha de Stereo + 1 liter/ha Bravo & 3 May 2006 & 225 \\
\hline & & & GS37 & 1.6 liter/ha Inputpro set +1 liter/ha Bravo & 16 May 2006 & \\
\hline & & & GS59 & 0.75 liter/ha Opus team +1 liter $/$ ha Bravo & 8 June 2006 & \\
\hline \multirow[t]{4}{*}{2007} & Pea & Control & $\ldots$ & No fungicide application & & 195 \\
\hline & & Treated & GS31 & 0.7 liter/ha de Stereo +1 liter/ha Bravo & 17 April 2007 & 195 \\
\hline & & & GS37 & 1.6 liter/ha Inputpro set + 1 liter/ha Bravo & 3 May 2007 & \\
\hline & & & GS59 & 0.75 liter/ha Opus team +1 liter/ha Bravo & 24 May 2007 & \\
\hline
\end{tabular}

\footnotetext{
y Growth stages defined according to Zadoks et al. (47).

${ }^{\mathrm{z}}$ Active ingredients of the fungicides are as follows: Stereo, active ingredients Prothioconazole $\left(250 \mathrm{~g} \mathrm{liter}^{-1}\right)$ and Spiroxamine $\left(500 \mathrm{~g} \mathrm{liter}{ }^{-1}\right)$; Bravo, active ingredient Chlorothalonil (500 $\left.\mathrm{g} \mathrm{liter}^{-1}\right)$; Input pro set, active ingredients Epoxiconazole $\left(84 \mathrm{~g} \mathrm{liter}^{-1}\right)$ and Fenpropimorph $\left(250 \mathrm{~g} \mathrm{liter}^{-1}\right)$; and Opus team, active ingredients Cyprodinil (250 $\left.\mathrm{g} \mathrm{liter}^{-1}\right)$ and Propiconazole $\left(62.5 \mathrm{~g} \mathrm{liter}^{-1}\right)$.
} 
effects of block: $Y_{i j k l m}=\vartheta+\alpha_{i}+\beta_{j}+\gamma_{k}+(a \beta)_{i j}+(\alpha \gamma)_{i k}+(\beta \gamma)_{j k}+$ $(a \beta \gamma)_{i j k}$ (fixed effects) and $b_{l}+\alpha b_{l}+\beta b_{l}+\gamma b_{l}+\varepsilon_{i j k l m}$ (random effects), where $\vartheta$ is the intercept term; $\alpha_{i}$ is the effect of the $i$ th leaf layer; $\beta_{j}$ is the effect of the $j$ th treatment; $\gamma_{k}$ is the effect of the $k$ th rater; $(a \beta)_{i j},(\alpha \gamma)_{i k,}(\beta \gamma)_{j k}$, and $(a \beta \gamma)_{i j k}$ are the fixed-effects interaction terms; $b_{l}$ is the random effect of block; $\alpha b_{i l}, \beta b_{j l}$, and $\gamma b_{k l}$ are the interaction terms of block with leaf layer, treatment, and rater, respectively; and $\varepsilon_{i j k l m}$ is the residual error term. The data were

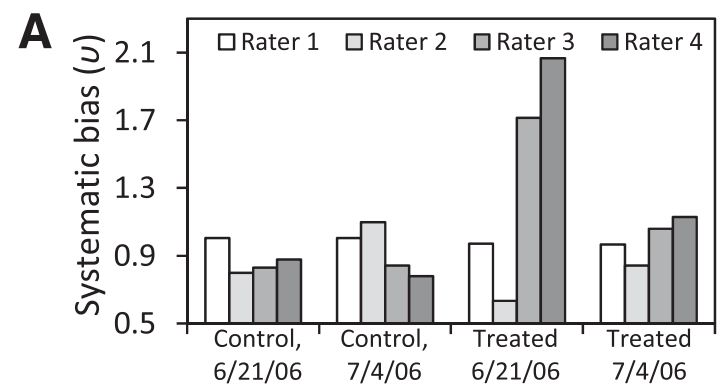

B

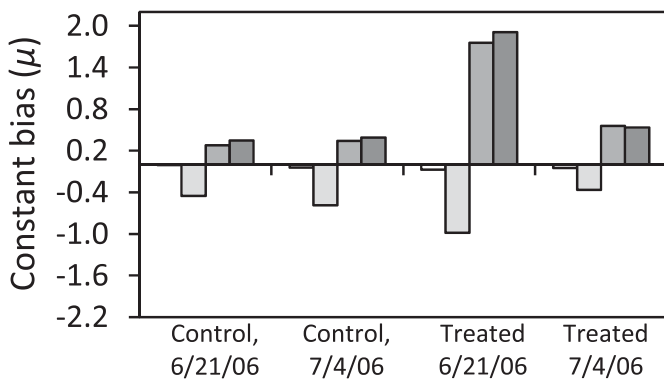

C

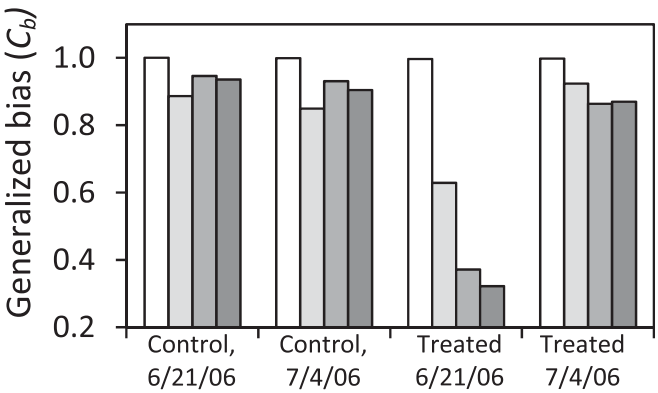

D

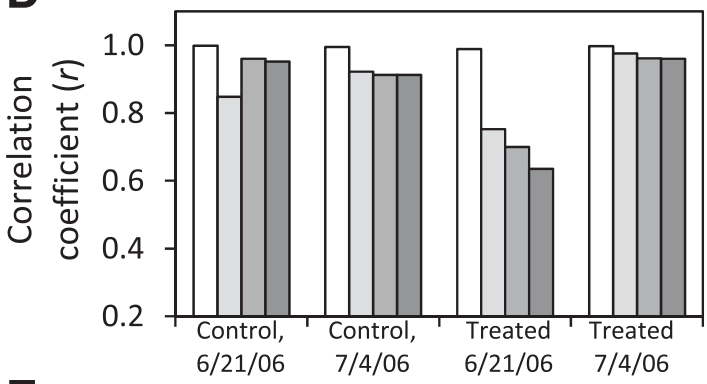

$\mathbf{E}$

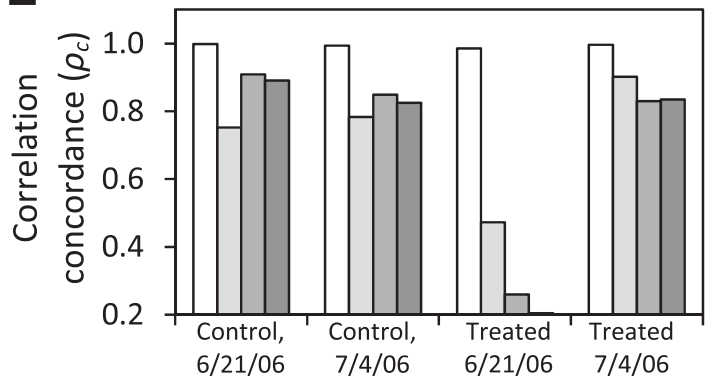

Fig. 1. Lin's concordance correlation analysis statistics comparing rater estimates for accuracy in relation to the actual values of severity of Septoria leaf blotch on control and fungicide-treated plots of winter wheat Achat at Everlange, the Grand Duchy of Luxembourg, in 2006. A, Scale bias (v); B, location bias ( $\mu$ ); C, generalized bias $\left(C_{b}\right)$; D, precision, measured by the correlation coefficient $(r)$; and $\mathbf{E}$, accuracy, measured by LCC coefficient $\left(\rho_{c}\right)$.

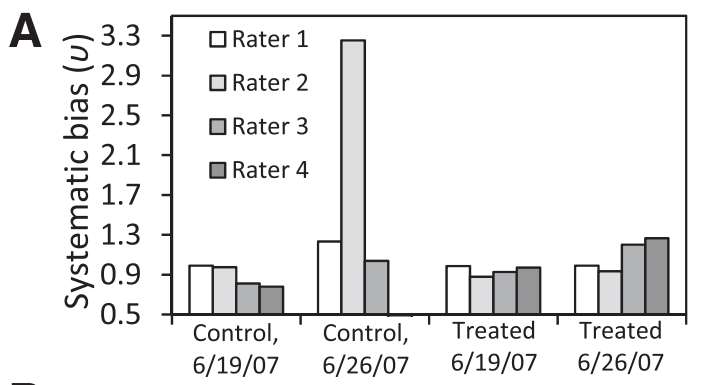

B

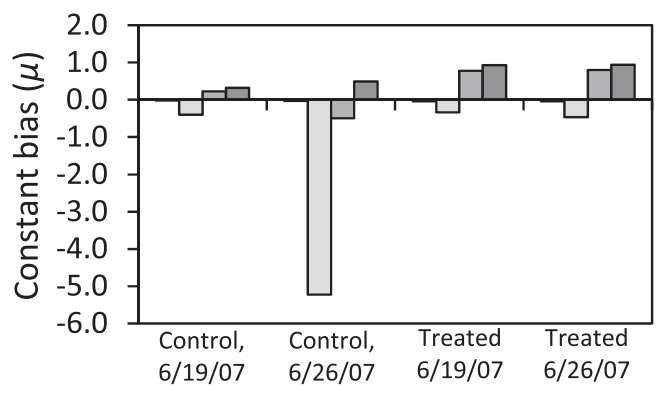

C
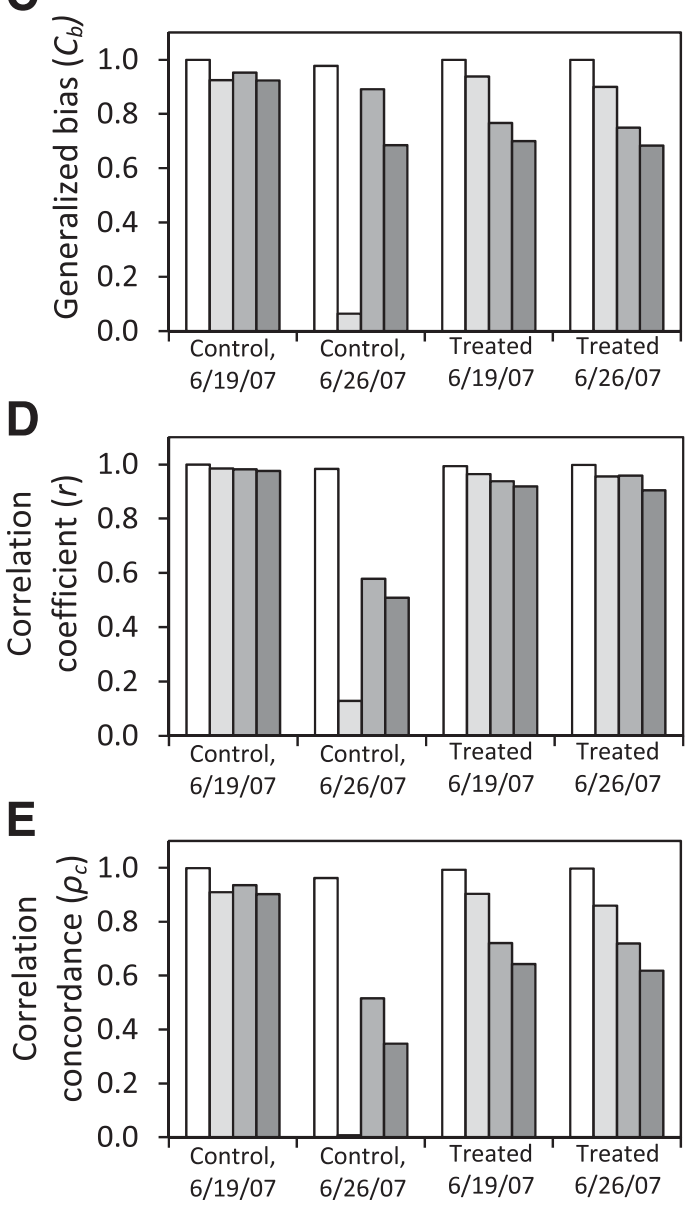

Fig. 2. Lin's concordance correlation (LCC) analysis statistics comparing rater estimates for accuracy in relation to the actual values of severity of Septoria leaf blotch on control and fungicide-treated plots of winter wheat Achat at Everlange, the Grand-Duchy of Luxembourg, in 2007. A, Scale bias (v); B, location bias $(\mu)$; $\mathbf{C}$, generalized bias $\left(C_{b}\right)$; $\mathbf{D}$, precision, measured by the correlation coefficient $(r)$; and $\mathbf{E}$, accuracy, measured by LCC coefficient $\left(\rho_{c}\right)$. 
assumed to be normally distributed, with equal variance and a logit link function (default for proc glimmix). On 26 June 2007, there was no term for leaf layer because only leaf layer F1 was assessed (F2 and F3 were senesced).

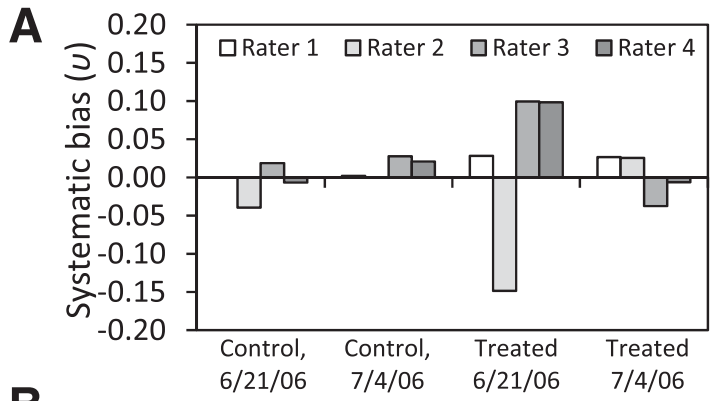

B
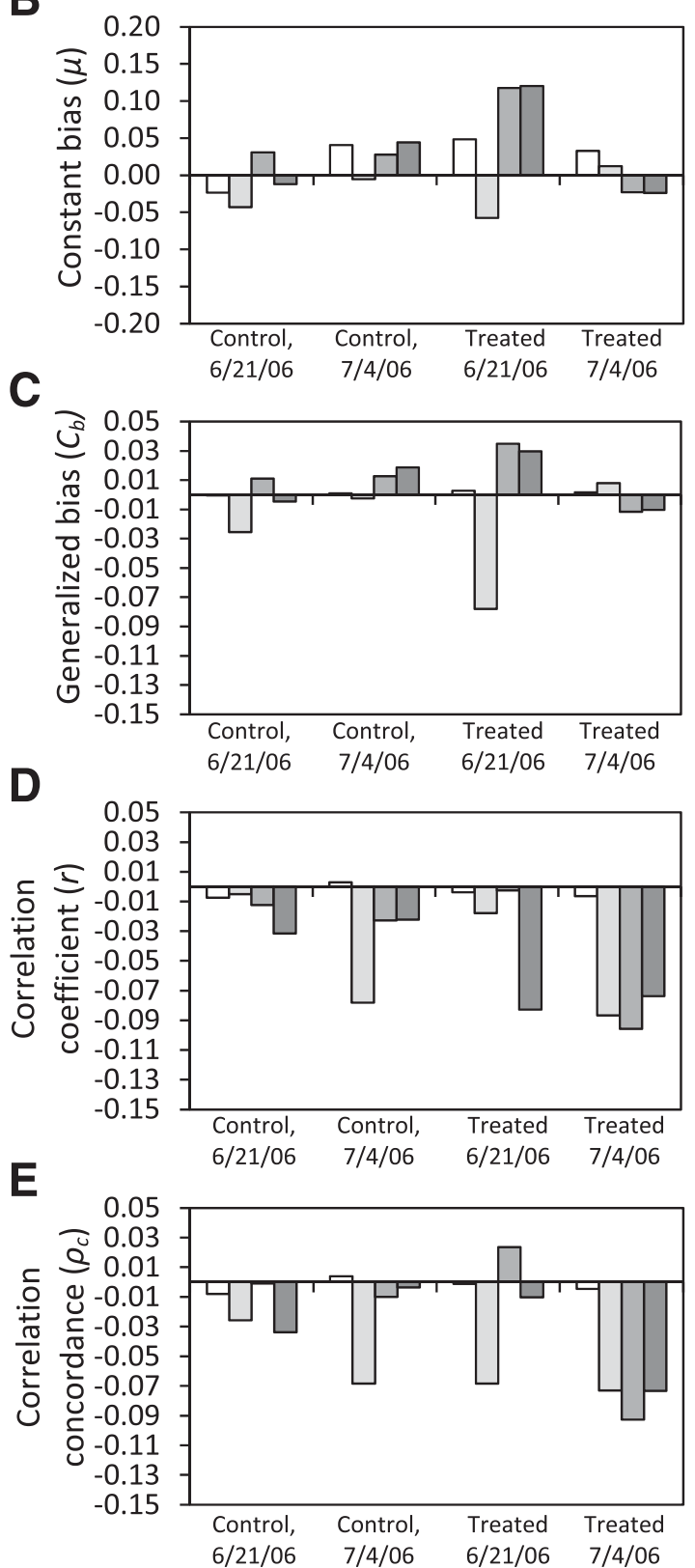

Fig. 3. When comparing Horsfall-Barratt-converted values with nearest percent estimates, Lin's concordance correlation (LCC) analysis statistics were used. The difference (gain or loss) for the two assessment methods with respect to the actual values of severity of Septoria leaf blotch on control and fungicide-treated plots of winter wheat Achat at Everlange, the Grand Duchy of Luxembourg, in 2006 are shown. A, Scale bias $(v)$; B, location bias $(\mu)$; C, generalized bias $\left(C_{b}\right) ; D$, precision, measured by the correlation coefficient $(r)$; and $\mathrm{E}$, accuracy, measured by LCC coefficient $\left(\rho_{c}\right)$.
In addition, analysis was performed for image analysis data and for each rater individually to mimic hypothesis testing using an automated system or different individuals (also with random effects of block): $Y_{i j}=\vartheta+\alpha_{i}+$ $\beta_{j}+(a \beta)_{i j}$ (fixed effects) and $b_{l}+\alpha b_{l}+\beta b_{l}+\varepsilon_{i j}$ (random effects), with

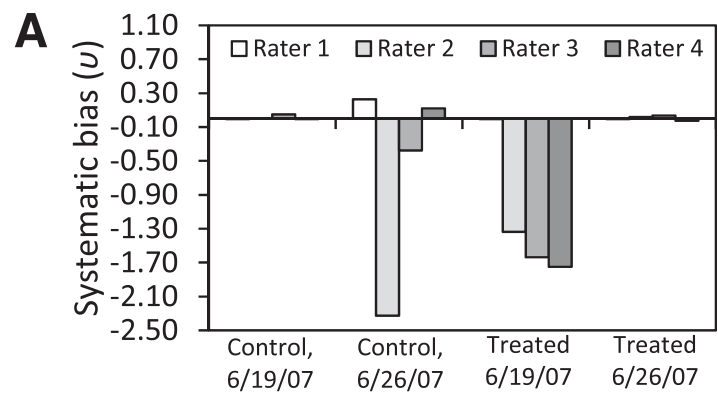

B

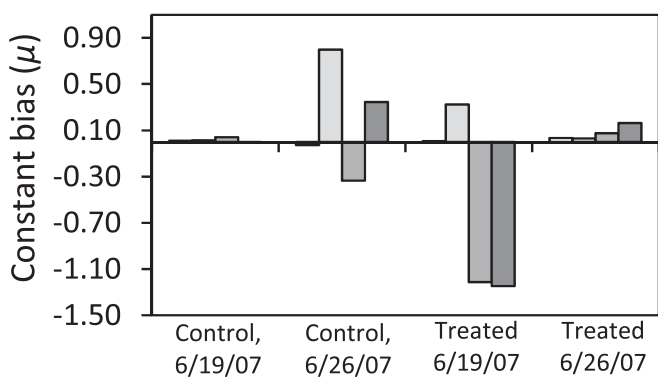

C
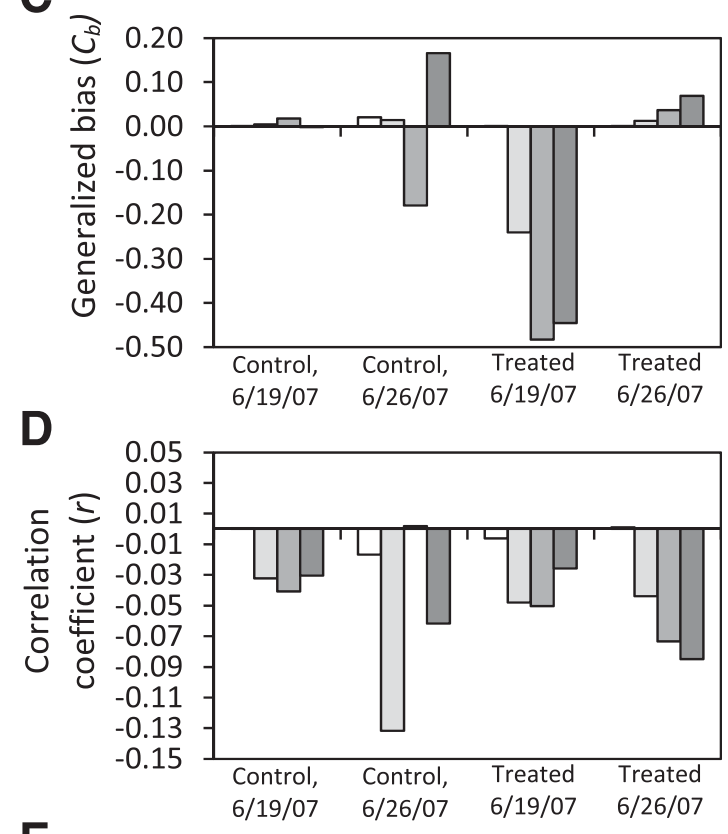

E

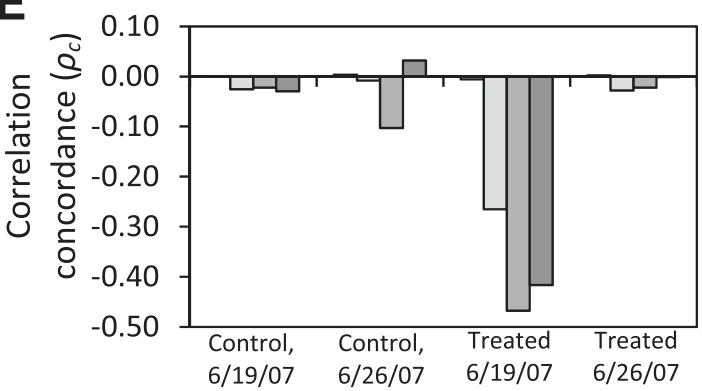

Fig. 4. When comparing Horsfall-Barratt-converted values with nearest percent estimates, Lin's concordance correlation (LCC) analysis statistics were used. The difference (gain or loss) for the two assessment methods with respect to the actual values of severity of Septoria leaf blotch on control and fungicide-treated plots of winter wheat Achat at Everlange, the Grand Duchy of Luxembourg, in 2007 are shown. A, Scale bias (v); B, location bias $(\mu)$; $\mathbf{C}$, generalized bias $\left(C_{b}\right)$; $\mathbf{D}$, precision, measured by the correlation coefficient $(r)$; and $\mathbf{E}$, accuracy, measured by LCC coefficient $\left(\rho_{c}\right)$. 
notation as above. Least square means were calculated (LSmeans statement) and post hoc means separation was by $t$ grouping $(\alpha=0.05)$.

\section{Results}

Accuracy and reliability of rater estimates of disease severity in fungicide-treated and control plots. LCC analysis demonstrated that estimates by rater 1 on both control and fungicide-treated plots had the least systematic or constant bias $(v=0.966$ to 1.004 , $\mu=-0.010$ to -0.072$)$, generalized bias $\left(C_{b}=0.997\right.$ to 0.999$)$, or loss of precision ( $r=0.989$ to 0.999 ), and had the greatest accuracy $\left(\rho_{c}=0.986\right.$ to 0.999$)$, with actual values on both dates in 2006 and 2007 on control and fungicide-treated plots (Figs. 1 and 2). Rater 2 showed severe systematic bias $(v=3.252)$ on control plots in 2007. Overall, in both 2006 and 2007, rater 2 tended to underestimate severity and showed some imprecision, with fair to poor accuracy in $2006\left(\rho_{\mathrm{c}}=0.473\right.$ to 0.902$)$ and terrible accuracy on control plots on 26 June $2007\left(\rho_{\mathrm{c}}=0.008\right)$. Raters 3 and 4 showed similar accuracy on control and fungicide-treated plots in both 2006 and 2007. Both raters tended to overestimate disease $(\mu=0.280$ to 1.756 , except rater
3 on control plots on 26 June 2007, where $\mu=-0.494)$ and displayed a range of generalized bias $\left(C_{b}=0.323\right.$ to 0.953$)$, precision $(r=0.508$ to 0.982$)$, and accuracy $\left(\rho_{\mathrm{c}}=0.205\right.$ to 0.936$)$, which was least on fungicide-treated plots on 21 June 2006 ( $\rho_{c}=0.205$ to 0.835 ). Overall, raters tended to have consistent characteristics of accuracy among treatments and between assessment dates (particularly rater 1) in estimating severity of SLB in both 2006 and 2007, despite some individual discrepancies. Rater 2 (who underestimated SLB severity) showed a reasonably consistent degree of bias, precision, and accuracy on all plots and dates, except on control plots on 26 June $2007\left(\rho_{c}=0.008\right)$. Raters 3 and 4 (who overestimated SLB severity) also showed more bias and less precision or accuracy on the fungicide-treated plots on 21 June 2006 and control plots on 26 June 2007 (rater 3: $\rho_{c}=0.260$ and 0.515 , respectively; and rater 4: $\rho_{c}=0.205$ and 0.348 , respectively).

Conversion of the estimates to the HB scale affected all measures of agreement in both 2006 and 2007 (Figs. 3 and 4). Interestingly, no measure of bias $\left(v, \mu\right.$, or $\left.C_{b}\right)$ was consistently improved or worsened by converting to the HB scale, regardless of plot treatment or assessment date. Although rater 1 showed at most a small change in bias, it
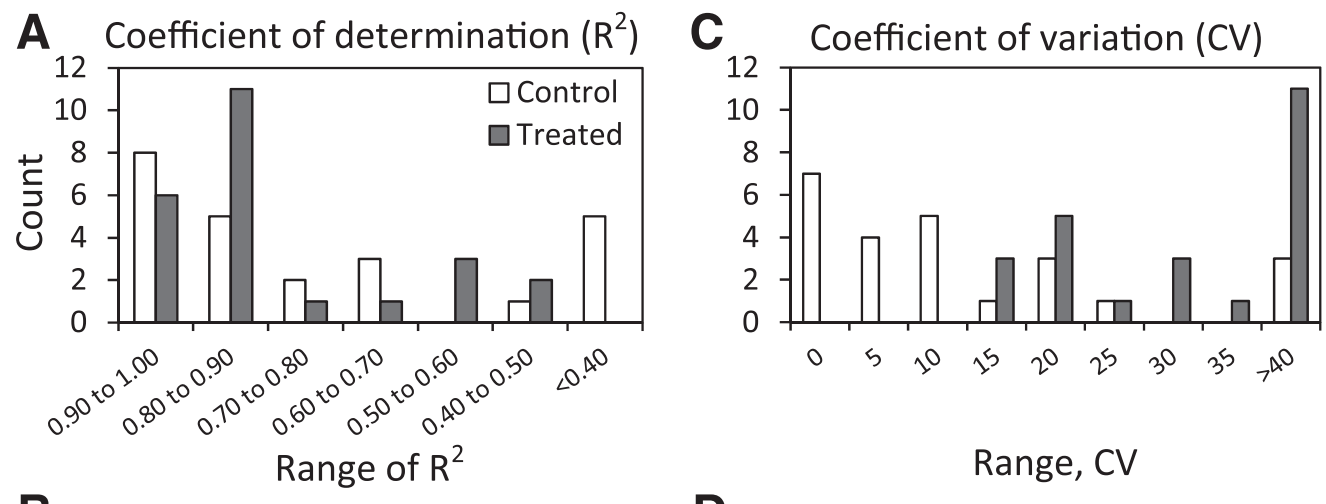

B
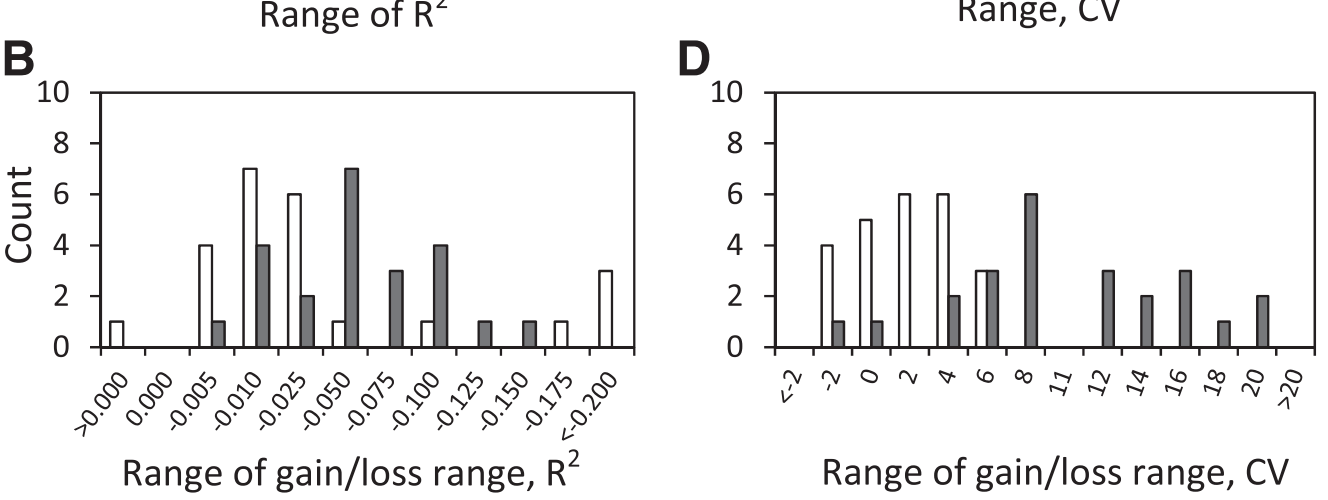

Fig. 5. Interrater reliability measured by $\mathbf{A}$, the coefficient of determination $\left(R^{2}\right)$ and $\mathbf{C}$, the coefficient of variation $(C V)$ comparing rater estimates of severity of Septoria leaf blotch on control and fungicide-treated plots of winter wheat Achat pairwise with each other at Everlange, the Grand Duchy of Luxembourg, in 2006 and 2007 combined. B and D, Frequency of the gain or loss in difference of the $R^{2}$ and the $\mathrm{CV}$ using either nearest percent estimates or Horsfall-Barratt-converted values, respectively

Table 2. Comparison of reliability (intraclass correlation coefficient $[\mathrm{ICC}, \rho]$ ) on estimates of the severity of Septoria leaf blotch on leaves of winter wheat Achat by different raters using nearest percent estimates (NPEs) or estimates converted to the Horsfall-Barratt (HB) scale on both control plots and plots receiving fungicide ${ }^{\mathrm{z}}$

\begin{tabular}{|c|c|c|c|c|c|c|}
\hline \multirow[b]{2}{*}{ Year } & \multirow[b]{2}{*}{ Date } & \multirow[b]{2}{*}{ Treatment } & \multicolumn{2}{|l|}{ NPEs } & \multicolumn{2}{|l|}{ HB } \\
\hline & & & ICC & $95 \%$ CIs & ICC & 95\% CIs \\
\hline \multirow{4}{*}{2006} & 21 June & Control & $0.95(F=84, P<0.0001)$ & $0.93-0.96$ & $0.94(F=31, P<0.0001)$ & $0.92-0.95$ \\
\hline & & Treated & $0.89(F=17, P<0.0001)$ & $0.86-0.92$ & $0.86(F=13, P<0.0001)$ & $0.82-0.89$ \\
\hline & 4 July & Control & $0.93(F=29, P<0.0001)$ & $0.90-0.95$ & $0.92(F=23, P<0.0001)$ & $0.89-0.94$ \\
\hline & & Treated & $0.97(F=68, P<0.0001)$ & $0.96-0.98$ & $0.94(F=34, P<0.0001)$ & $0.92-0.96$ \\
\hline \multirow[t]{4}{*}{2007} & 19 June & Control & $0.98(F=105, P<0.0001)$ & $0.97-0.99$ & $0.97(F=66, P<0.0001)$ & $0.96-0.98$ \\
\hline & & Treated & $0.97(F=58, P<0.0001)$ & $0.96-0.98$ & $0.95(F=36, P<0.0001)$ & $0.93-0.96$ \\
\hline & 26 July & Control & $0.92(F=24, P<0.0001)$ & $0.86-0.95$ & $0.88(F=15, P<0.0001)$ & $0.80-0.93$ \\
\hline & & Treated & $0.98(F=84, P<0.0001)$ & $0.97-0.99$ & $0.93(F=29, P<0.0001)$ & $0.88-0.96$ \\
\hline
\end{tabular}

\footnotetext{
${ }^{\mathrm{z}}$ The intraclass correlation $(\rho)$ compares between-subject and within-subject variance, accounting for chance correspondence of the variance between the two
} measurements. The ICC and its confidence limits $(\mathrm{CI}=$ confidence interval) was calculated using a SAS macro (26). 
was not a consistent gain or loss. Raters 2, 3, and 4 all showed a range in gain or loss in bias, with no obvious consistent effect; although, in some cases, the change was a substantial loss (for example, on 19 June 2007, for rater 2 on control plots and raters 2, 3, and 4 on fungicide-treated plots, the loss in $v$ was $-2.328,-1.337,-1.369$, and -1.750 , respectively). However, there was a more consistent effect across raters, dates, and treatments considering precision $(r)$ and accuracy $\left(\rho_{c}\right)$ when HB-converted values were used. Converted estimates of rater 1 showed a very slight gain and, more often, a loss of precision ( $r=-0.017$ to 0.004$)$ and accuracy $\left(\rho_{c}=-0.008\right.$ to 0.004$)$. Raters 2, 3, and 4 most often showed a more severe loss of precision ( $r=-0.468$ to 0.032$)$ and accuracy $\left(\rho_{\mathrm{c}}=-0.132\right.$ to 0.003$)$.

Interrater reliability, measured by the coefficient of determination on both the control and fungicide-treated plots, spanned a similar range (Fig. 5A), with conversion to the $\mathrm{HB}$ scale most often resulting in a loss of reliability of -0.005 to -0.150 (Fig. 5B). Only a single pairwise comparison on control plots increased in reliability with the HB-converted data. The CV was least on control plots and greatest on fungicide-treated plots (Fig. 5C), indicating that data tended to be more dispersed at those severities (lower) encountered on fungicidetreated plots. Furthermore, conversion to the HB scale resulted in an increase in dispersion of the estimates of -2.0 to $>-20.0$ (Fig. 5D). However, the ICCs (Table 2) for the estimates from dates and plots indicated that, in most cases, the interrater reliability was good $(\rho=0.88$ to 0.98 ). Only on 26 July 2007 were the NPEs and HB interrater reliabilities significantly differed based on the $95 \%$ confidence intervals, although some differences did exist between control and treated plots (NPEs on 21 June 2006, 4 July 2006, and 26 July 2007 and HB estimates on 21 June 2006).

A comparison of mean estimates of disease severity. The analysis of the data from fungicide-treated and control plots showed a similar trend on each date (Table 3), with consistent main effects of leaf position, treatment, rater, and a leaf position-rater interaction (except on 26 June 2007, when only leaf position F1 was assessed).

Based on the least square means for rater (image analysis and raters 1 to 4 ), there were significant differences among raters on each assessment date but the rater mean estimates of disease severity were most often different from that measured using image analysis regardless of whether using NPEs or HB-converted values (Table 4). Only estimates by rater 1 were consistently sufficiently accurate to ensure that the estimate of mean disease severity was not significantly different from the actual mean severity. All other raters were consistently significantly different in their estimates from the actual mean using either NPEs or the HB scale, and frequently significantly different from each other and from rater $1(F=151$ to $1260, P=0.001$ to $<0.0001)$. Rater 2 consistently underestimated the mean severity $(-8.4$ to $-9.6 \%)$, while raters 3 and 4 both overestimated the severity of disease $(+5.3$ to $+12.2 \%)$. Rater 1's deviation from the actual mean disease was -0.1 to $-0.6 \%$. Although this suggests consistency in the characteristics of a particular rater's ability, it also demonstrates the ramifications of bias in estimating severity, despite raters most often having good agreement with the actual values on individual plots and dates, as measured using LCCC and described in the previous section. In one incidence (26 July 2007), converting to the HB scale changed the means ranking of the raters, an error that can have ramifications for hypothesis testing. It should be noted that this was also based on the smallest sample size $(n=20$ leaves per rater-treatment combination, compared with $n=60$ for the other dates). Sample size affects type II error raters $(3,9)$.

Treatment effects. The analysis demonstrated a consistent effect of fungicide treatment based on measurement by image analysis or estimates by raters 1 to 4 on each assessment date in both 2006 (Table 5) and 2007 (Table 6), regardless of whether NPEs or the HB-converted data were used. In all comparisons, the actual difference (measured by image analysis) between treatment means was substantial, when based on either NPEs (32.1 to 86.0) or HBconverted data (32.0 to 86.0). However, most often there was a slight decline in the $F$ value when using the HB scale. The $F$ value ( $P$ values) for NPE estimates ranged from $116(0.002)$ to $276(0.0005)$ and for HB-converted values ranged from $101(0.002)$ to $270(0.0005)$ in
2006, and for NPE estimates from $164(0.001)$ to $1,952(<0.0001)$ and for HB-converted values ranged from $126(0.002)$ to $1,633(<0.0001)$ in 2007. These results demonstrate the slightly depressive effect the less precise HB scale can have on $F$ and $P$ values, even with the substantial sample size used and large treatment differences found in these experiments.

\section{Discussion}

Inaccuracy and unreliability associated with visual estimates of disease severity on individual leaves is well established $(5,28,31,34,35,38,46)$. However, examples of the ramifications of inaccurate or unreliable disease assessments on the outcome of data analysis are less well explored $(3,9,42,44)$, partly because it is not the objective of most studies and, thus, resources are not invested in obtaining the multiple measurements or assessments on the same leaves on plots receiving different treatments that are required to allow this kind of comparison.

There were no type II errors (i.e., failure to reject the null hypotheses when the null hypothesis is false) observed between fungicidetreated and control plots, despite significant differences in mean estimates of disease severity by different raters. This was probably due to the fact that the differences between the means of treatments were invariably large and, thus, the risk of a type II error was low (3), although type II errors due to rater inaccuracy have been

Table 3. Type III fixed effects of the analysis of the severity of Septoria leaf blotch on leaves of winter wheat Achat on fungicide-treated and control plots as measured by image analysis or estimated by different raters using nearest percent estimates (NPEs) or estimates converted to the HorsfallBarratt (HB) scale at Everlange, the Grand Duchy of Luxembourg, in 2006 and $2007^{\mathrm{w}}$

\begin{tabular}{|c|c|c|c|}
\hline \multirow[b]{2}{*}{ Date, effect ${ }^{x}$} & \multirow[b]{2}{*}{ Num/Den DFy } & \multicolumn{2}{|c|}{$F$ value ( $P$ value $)$} \\
\hline & & NPEs & HB \\
\hline \multicolumn{4}{|l|}{21 June 2006} \\
\hline Leaf & $2 / 6$ & $163(<0.0001)$ & $159(<0.0001)$ \\
\hline Treatment & $1 / 3$ & $404(0.0003)$ & $319(0.0004)$ \\
\hline Rater & $4 / 12$ & $48(<0.0001)$ & $49(<0.0001)$ \\
\hline Leaf-treatment & $2 / 66$ & $167(<0.0001)$ & $153(<0.0001)$ \\
\hline Leaf-rater & $8 / 66$ & $1(0.3)$ & $2(0.1)$ \\
\hline Treatment-rater & $4 / 66$ & $3(0.04)$ & $3(0.04)$ \\
\hline Leaf-treatment-rater & $8 / 66$ & $1(0.2)$ & $2(0.1)$ \\
\hline \multicolumn{4}{|l|}{4 July 2006} \\
\hline Leaf & $2 / 6$ & $15(0.005)$ & $18(0.003)$ \\
\hline Treatment & $1 / 3$ & $151(0.001)$ & $144(0.001)$ \\
\hline Rater & $4 / 12$ & $24(<0.0001)$ & $21(<0.0001)$ \\
\hline Leaf-treatment & $2 / 51$ & $11(<0.0001)$ & $6(0.007)$ \\
\hline Leaf-rater & $8 / 51$ & $<1(1.0)$ & $<1(0.9)$ \\
\hline Treatment-rater & $4 / 51$ & $1(0.4)$ & $1(0.3)$ \\
\hline Leaf-treatment-rater & $8 / 51$ & $1(0.4)$ & $1(0.6)$ \\
\hline \multicolumn{4}{|l|}{19 June 2007} \\
\hline Leaf & $2 / 6$ & $36(0.0004)$ & $36(0.0005)$ \\
\hline Treatment & $1 / 3$ & $283(0.0005)$ & $223(0.0007)$ \\
\hline Rater & $4 / 12$ & $40(<0.0001)$ & $40(<0.0001)$ \\
\hline Leaf-treatment & $2 / 66$ & $62(<0.0001)$ & $60(<0.0001)$ \\
\hline Leaf-rater & $8 / 66$ & $1(0.8)$ & $1(0.8)$ \\
\hline Treatment-rater & $4 / 66$ & $2(0.1)$ & $2(0.1)$ \\
\hline Leaf-treatment-rater & $8 / 66$ & $1(0.4)$ & $1(0.4)$ \\
\hline \multicolumn{4}{|l|}{26 June $2007^{z}$} \\
\hline Treatment & $1 / 3$ & $1,193(<0.0001)$ & $1,260(<0.0001)$ \\
\hline Rater & $4 / 12$ & $52(<0.0001)$ & $36(<0.0001)$ \\
\hline Treatment-rater & $4 / 153$ & $16(<0.0001)$ & $11(<0.0001)$ \\
\hline
\end{tabular}

${ }^{w}$ For the generalized linear mixed model, the Akaike's Information Criterion (AIC) for NPEs on 21 June $2006=4,639,4$ July $2006=4,120$, 19 June 2007 $=4,695$, and 26 June $2007=1,131$. AIC for HB-converted values on 21 June $2006=4,660$, 4 July $2006=4,176,19$ June $2007=4,701$, and 26 June $2007=1,171$. Effects of block were treated as random.

${ }^{\mathrm{x}}$ Leaf $=\mathrm{F} 1$ to $\mathrm{F} 3$, Treatment $=$ fungicide-treated or control, Rater $=$ image analysis or raters 1 to 4 .

y Numerator and denominator degrees of freedom.

${ }^{\mathrm{z}}$ Only leaf layer F1 was assessed using image analysis and by all raters on 26 June 2007. 
observed in a prior study (38). The results of our study compare well with those of Steddom et al. (42), who were able to differentiate fungicide treatments in plots of wheat. However, rater estimates in the Steddom et al. study were performed on the whole plot, while image analysis measurements were made on a subsample of flag leaves (42), precluding a direct comparison. Furthermore, they made no comment on inaccuracies of estimates of mean severity; whereas, in the current study, raters 3 and 4 overestimated while rater 2 underestimated severity. However, despite rater bias in estimates of the mean, it was still possible to differentiate treatments. If treatment means were closer, those raters with less precise estimates might fail to differentiate treatments, but this was not quantified (3). There are two components to disease assessment: one is disease identification and the other is measurement accuracy. All raters received training in identification and disease assessment prior to the task (and, indeed, by the end of the assessments in 2007 even the inexperienced raters might be considered experienced) and, thus, the overestimation by raters 3 and 4 is more likely due to measurement inaccuracy.

However, individuals were for the most part surprisingly consistent in their characteristics to over- or underestimate the mean severity of disease, regardless of date, treatment, or actual mean severity (5.4 to $99.2 \%$ mean leaf area diseased on the various dates and treatments, according to image analysis) in this study. This was borne out by the LCC analysis, which also suggested a fairly consistent pattern for each rater, with occasional shifts in the direction or magnitude of bias, precision, or accuracy. However, these shifts did not alter the

Table 4. LSmeans severity of Septoria leaf blotch on leaves of winter wheat Achat, as measured by image analysis (IA) or estimated by different raters using nearest percent estimate (NPE) or estimates converted to the Horsfall-Barratt (HB) scale at Everlange, the Grand Duchy of Luxembourg, in 2006 and $2007^{z}$

\begin{tabular}{|c|c|c|c|c|c|c|}
\hline \multirow[b]{2}{*}{ Year } & \multirow[b]{2}{*}{ Date } & \multirow[b]{2}{*}{ Method, rater } & \multicolumn{2}{|c|}{ NPE } & \multicolumn{2}{|c|}{ HB } \\
\hline & & & Mean severity & $F$ value ( $P$ value $)$ & Mean severity & $F$ value ( $P$ value $)$ \\
\hline \multirow[t]{10}{*}{2006} & 21 June & IA & $21.4 \mathrm{~b}$ & $404(0.0003)$ & $21.3 \mathrm{~b}$ & $319(0.0004)$ \\
\hline & & Rater 1 & $21.1 \mathrm{~b}$ & $\ldots$ & $20.7 \mathrm{~b}$ & $\ldots$ \\
\hline & & Rater 2 & $13.1 \mathrm{c}$ & $\ldots$ & $12.4 \mathrm{c}$ & $\ldots$ \\
\hline & & Rater 3 & $31.0 \mathrm{a}$ & $\ldots$ & $30.6 \mathrm{a}$ & $\ldots$ \\
\hline & & Rater 4 & $33.2 \mathrm{a}$ & & $33.5 \mathrm{a}$ & $\ldots$ \\
\hline & 4 July & IA & $51.0 \mathrm{~b}$ & $151(0.001)$ & $50.5 \mathrm{~b}$ & $144(0.001)$ \\
\hline & & Rater 1 & $50.4 \mathrm{~b}$ & $\ldots$ & $50.4 \mathrm{~b}$ & $\ldots$ \\
\hline & & Rater 2 & $41.5 \mathrm{c}$ & $\ldots$ & $40.6 \mathrm{c}$ & $\ldots$ \\
\hline & & Rater 3 & $59.6 \mathrm{a}$ & $\ldots$ & $58.9 \mathrm{a}$ & $\ldots$ \\
\hline & & Rater 4 & $59.7 \mathrm{a}$ & $\ldots$ & $58.8 \mathrm{a}$ & $\ldots$ \\
\hline \multirow[t]{10}{*}{2007} & 19 June & IA & $40.6 \mathrm{~b}$ & $283(0.0005)$ & $40.5 \mathrm{~b}$ & $223(0.0007)$ \\
\hline & & Rater 1 & $40.0 \mathrm{~b}$ & $\ldots$ & $40.0 \mathrm{~b}$ & $\ldots$ \\
\hline & & Rater 2 & $32.5 \mathrm{c}$ & $\ldots$ & $32.1 \mathrm{c}$ & $\ldots$ \\
\hline & & Rater 3 & $49.4 \mathrm{a}$ & $\ldots$ & $49.0 \mathrm{a}$ & $\ldots$ \\
\hline & & Rater 4 & $51.7 \mathrm{a}$ & $\ldots$ & $51.3 \mathrm{a}$ & $\ldots$ \\
\hline & 26 July & IA & $56.1 \mathrm{c}$ & $1,193(<0.0001)$ & $56.2 \mathrm{~b}$ & $1,260(<0.0001)$ \\
\hline & & Rater 1 & $55.7 \mathrm{c}$ & $\ldots$ & $55.9 \mathrm{~b}$ & $\ldots$ \\
\hline & & Rater 2 & $46.5 \mathrm{~d}$ & $\ldots$ & $46.6 \mathrm{c}$ & $\ldots$ \\
\hline & & Rater 3 & $61.4 \mathrm{~b}$ & $\ldots$ & $61.6 \mathrm{a}$ & $\ldots$ \\
\hline & & Rater 4 & $64.8 \mathrm{a}$ & $\ldots$ & $63.4 \mathrm{a}$ & $\ldots$ \\
\hline
\end{tabular}

${ }^{\mathrm{z}}$ Letters indicate significant differences between the means for IA and raters based on Tukey's HSD test $(\alpha=0.05)$.

Table 5. Effect of fungicide treatment on severity of Septoria leaf blotch on leaves of winter wheat Achat, as measured by image analysis (IA) or estimated by different raters using nearest percent estimate (NPE) or estimates converted to the Horsfall-Barratt (HB) scale at Everlange, the Grand Duchy of Luxembourg, in $2006^{\mathrm{z}}$

\begin{tabular}{|c|c|c|c|c|c|c|}
\hline \multirow[b]{2}{*}{ Date } & \multirow[b]{2}{*}{ Method, rater } & \multirow[b]{2}{*}{ Plot treatment } & \multicolumn{2}{|c|}{ NPE } & \multicolumn{2}{|c|}{ HB } \\
\hline & & & Severity & $F$ value ( $P$ value) & Severity & $F$ value ( $P$ value $)$ \\
\hline \multirow[t]{10}{*}{21 June } & IA & Control & $37.5 \mathrm{a}$ & $154(0.001)$ & $37.3 \mathrm{a}$ & $147(0.001)$ \\
\hline & & Treated & $5.4 \mathrm{~b}$ & & $5.3 \mathrm{~b}$ & \\
\hline & Rater 1 & Control & $37.2 \mathrm{a}$ & $154(0.001)$ & $36.2 \mathrm{a}$ & $141(0.001)$ \\
\hline & & Treated & $5.1 \mathrm{~b}$ & $\ldots$ & $5.2 \mathrm{~b}$ & $\ldots$ \\
\hline & Rater 2 & Control & $24.5 \mathrm{a}$ & $116(0.002)$ & $23.4 \mathrm{a}$ & $101(0.002)$ \\
\hline & & Treated & $1.7 \mathrm{~b}$ & $\ldots$ & $1.4 \mathrm{~b}$ & $\ldots$ \\
\hline & Rater 3 & Control & $45.7 \mathrm{a}$ & $163(0.001)$ & $44.7 \mathrm{a}$ & $137(0.001)$ \\
\hline & & Treated & $16.3 \mathrm{~b}$ & $\ldots$ & $16.5 \mathrm{~b}$ & $\ldots$ \\
\hline & Rater 4 & Control & $48.0 \mathrm{a}$ & $168(0.001)$ & $48.2 \mathrm{a}$ & $167(0.001)$ \\
\hline & & Treated & $18.4 \mathrm{~b}$ & $\ldots$ & $18.8 \mathrm{~b}$ & $\ldots$ \\
\hline \multirow[t]{10}{*}{4 July } & IA & Control & $80.4 \mathrm{a}$ & $262(0.0005)$ & $79.8 \mathrm{a}$ & $262(0.0005)$ \\
\hline & & Treated & $23.9 \mathrm{~b}$ & $\ldots$ & $22.8 \mathrm{~b}$ & $\ldots$ \\
\hline & Rater 1 & Control & 79.9 a & $276(0.0005)$ & $80.0 \mathrm{a}$ & $270(0.0005)$ \\
\hline & & Treated & $23.0 \mathrm{~b}$ & $\ldots$ & $22.5 \mathrm{~b}$ & $\ldots$ \\
\hline & Rater 2 & Control & $68.8 \mathrm{a}$ & $133(0.001)$ & $66.7 \mathrm{a}$ & $108(0.001)$ \\
\hline & & Treated & $17.2 \mathrm{~b}$ & $\ldots$ & $16.5 \mathrm{~b}$ & $\ldots$ \\
\hline & Rater 3 & Control & $85.9 \mathrm{a}$ & $152(0.001)$ & $85.5 \mathrm{a}$ & $187(0.0008)$ \\
\hline & & Treated & $35.5 \mathrm{~b}$ & $\ldots$ & $34.4 \mathrm{~b}$ & $\ldots$ \\
\hline & Rater 4 & Control & 85.9 a & $131(0.001)$ & $85.1 \mathrm{a}$ & $128(0.001)$ \\
\hline & & Treated & $35.3 \mathrm{~b}$ & $\ldots$ & $34.1 \mathrm{~b}$ & $\ldots$ \\
\hline
\end{tabular}

\footnotetext{
${ }^{\mathrm{z}}$ Letters indicate significant differences between the means for control and fungicide-treated plots for each rater based on Tukey's HSD test $(\alpha=0.05)$.
} 
rater's characteristic to over- or underestimate the mean severity of disease compared with the actual value measured by image analysis. Rater ability is known to vary $(8,34,35,40)$. In relation to this, the four raters showed a range of ability from accurate (rater 1) to those who overestimated (raters 3 and 4) and underestimated (rater 2) disease severity. Thus, a good range of ability was represented.

Interrater reliability measured using the coefficient of determination was variable depending on the rater pair in question and the particular treatment and date, which was borne out by the $\mathrm{CV}$, which also suggested a range in variability among individual rater pairs, as would be expected given the propensity of certain raters to overor underestimate severity. However, the overall effect on the ICC, which is a single measure of the reliability among all four raters on each date for each treatment, was relatively small and reflects the different facets of reliability measured by these statistics.

The impact of different disease assessment scales such as the HB scale on accuracy and precision of estimates has been studied previously $(3,9)$, although the effect on treatment means and treatment differences is less well characterized. In this study, there was no type II error caused by converting the data to the HB scale for comparing fungicide-treated and control plots but there was a change in means separation ranking of image analysis measurement and rater estimates on 26 July 2007 (Table 4), which demonstrates the potential risk associated with using an assessment method that alters the accuracy or precision of the data, especially if sample size is inadequate. On the date in question, sample size was only one-third $(n=20)$ that of the sample size on the other dates and treatments. Furthermore, differences between means were large (32.1 to $86.0 \%$, depending on assessment date and year) but if differences between means were smaller, risks of type II errors would be increased (3). Indeed, in most cases, the $F$ value of the analysis was slightly lower when using data based on HB-converted values compared with the NPEs, and these data assumed that the HB estimates would be in the same category as the NPE, which is not necessarily the case and might further increase error $(3,9)$. However, although use of the HB scale most often increases the variability of the data (as demonstrated by the consistent decrease in the correlation coefficient), neither NPEs nor HB-converted values appeared to be more biased or less accurate in this study.

Diversity in ability to estimate disease severity among raters is an issue that can be dealt with by deploying raters appropriately.
Although type II errors are possible (3), there is also a theoretical possibility that raters could inadvertently commit a type I error (rejecting $\mathrm{H}_{0}$, when no difference actually exists between treatments) due to biases in disease assessment. This risk is greatest when multiple assessors are rating disease in the same experiment, especially if they are not assessing plots on a replicate basis. Thus, if a rater were to overestimate disease compared with a rater who is either accurate or who underestimates disease, and these raters assessed more replicates of certain treatments, an analysis might show differences between treatments when this should really be attributed to differences between raters. This affirms the already recognized importance of following a strict protocol when deploying multiple raters in an experiment. Any individual rater should assess complete replicates of all treatments so as to spread any inherent bias or imprecision evenly across those treatments. We did not observe any type I errors in this study.

In an analysis on disease assessment ability of raters assessing disease on wheat (14), the characteristics of the same four raters were analyzed after separating the percent scale into 10 equal-sized classes of $10 \%$. The results showed that, when subdivided into consecutive $10 \%$ ranges, raters were most often very inaccurate, biased, and imprecise, although there was no obvious pattern, except that overestimates were most consistent among raters at 0 to $10 \%$ and underestimates most consistent at 90 to $100 \%$. Furthermore, Bock et al. (7) observed that estimates in the ranges of 0 to 6 and 6 to $25 \%$ disease severity generally showed less agreement with actual values compared with estimates in the range 25 to $75 \%$, and Sherwood (40) has demonstrated that many raters tend to overestimate at disease severities $<10 \%$. It is over this range of disease severity that many plant diseases occur (21), which emphasizes the need to establish the accuracy of raters prior to taking assessments. These data confirm and extend the results of other studies over the last 30 years that have demonstrated the range of ability among both experienced and inexperienced visual raters in many different pathosystems $(1,4,14,31,34,40,46)$.

The importance of disease assessment training is recognized-for example, using software such as Distrain or Disease.Pro $(1,37,45)$ and using assessment aids such as SADs $(12,16,19,20,43,46)$ - but disadvantages of visual assessment remains: raters tire and lose concentration, training may need to be repeated regularly to maintain accuracy and reliability, and visual assessment can be destructive if

Table 6. Effect of fungicide treatment on severity of Septoria leaf blotch on leaves of winter wheat Achat, as measured by image analysis (IA) or estimated by different raters using nearest percent estimate (NPE) or estimates converted to the Horsfall-Barratt (HB) scale at Everlange, the Grand Duchy of Luxembourg, in $2007^{\mathrm{z}}$

\begin{tabular}{|c|c|c|c|c|c|c|}
\hline \multirow[b]{2}{*}{ Date } & \multirow[b]{2}{*}{ Method, rater } & \multirow[b]{2}{*}{ Plot treatment } & \multicolumn{2}{|c|}{ NPE } & \multicolumn{2}{|c|}{ HB } \\
\hline & & & Severity & $F$ value ( $P$ value) & Severity & $F$ value ( $P$ value $)$ \\
\hline \multirow[t]{10}{*}{19 June } & IA & Control & $70.1 \mathrm{a}$ & $288(0.0004)$ & $69.9 \mathrm{a}$ & $256(0.0005)$ \\
\hline & & Treated & $10.6 \mathrm{~b}$ & & $11.0 \mathrm{~b}$ & \\
\hline & Rater 1 & Control & $70.1 \mathrm{a}$ & $285(0.0005)$ & $69.5 \mathrm{a}$ & $265(0.0005)$ \\
\hline & & Treated & $10.0 \mathrm{~b}$ & $\ldots$ & $10.5 \mathrm{~b}$ & $\ldots$ \\
\hline & Rater 2 & Control & $59.4 \mathrm{a}$ & $164(0.001)$ & $58.8 \mathrm{a}$ & $126(0.002)$ \\
\hline & & Treated & $5.7 \mathrm{~b}$ & $\ldots$ & $5.4 \mathrm{~b}$ & $\ldots$ \\
\hline & Rater 3 & Control & $76.6 \mathrm{a}$ & $309(0.0004)$ & $74.9 \mathrm{a}$ & $170(0.001)$ \\
\hline & & Treated & $22.2 \mathrm{~b}$ & $\ldots$ & $22.8 \mathrm{~b}$ & $\ldots$ \\
\hline & Rater 4 & Control & $78.7 \mathrm{a}$ & $318(0.0004)$ & $78.0 \mathrm{a}$ & $260(0.0005)$ \\
\hline & & Treated & $22.2 \mathrm{~b}$ & $\ldots$ & $24.7 \mathrm{~b}$ & $\ldots$ \\
\hline \multirow[t]{10}{*}{26 June } & IA & Control & $99.2 \mathrm{a}$ & $1,129(<0.0001)$ & $99.3 \mathrm{a}$ & $1,242(<0.0001)$ \\
\hline & & Treated & $13.2 \mathrm{~b}$ & $\ldots$ & $13.3 \mathrm{~b}$ & $\ldots$ \\
\hline & Rater 1 & Control & $98.9 \mathrm{a}$ & $1,179(<0.0001)$ & $99.1 \mathrm{a}$ & $935(<0.0001)$ \\
\hline & & Treated & $12.5 \mathrm{~b}$ & & $12.8 \mathrm{~b}$ & $\ldots$ \\
\hline & Rater 2 & Control & $87.5 \mathrm{a}$ & $1,952(<0.0001)$ & $87.6 \mathrm{a}$ & $1,633(<0.0001)$ \\
\hline & & Treated & $5.6 \mathrm{~b}$ & $\ldots$ & $5.7 \mathrm{~b}$ & $\ldots$ \\
\hline & Rater 3 & Control & $98.3 \mathrm{a}$ & $736(0.0001)$ & $97.9 \mathrm{a}$ & $591(0.0002)$ \\
\hline & & Treated & $24.7 \mathrm{~b}$ & & $25.5 \mathrm{~b}$ & $\ldots$ \\
\hline & Rater 4 & Control & $99.6 \mathrm{a}$ & $771(0.0001)$ & $99.5 \mathrm{a}$ & $919(<0.0001)$ \\
\hline & & Treated & $30.2 \mathrm{~b}$ & $\ldots$ & $27.5 \mathrm{~b}$ & $\ldots$ \\
\hline
\end{tabular}

${ }^{\mathrm{z}}$ Letters indicate significant differences between the means for control and fungicide-treated plots for each rater based on Tukey’s HSD test ( $\left.\alpha=0.05\right)$. 
samples are collected in the field for later assessment in the laboratory. Of course, measurements by image analysis can also have errors due to the operator, image characteristics, image compression, reflection and color inconsistencies, or other artifacts $(41,42)$, although most of these are generally not thought to be major sources of error. Furthermore, image analysis methods have been compared in at least one study (28) and found to be similar.

Very few studies have compared actual disease severity (here measured by image analysis) and estimated severity by different raters for treatment effects (38). The results of that study and the current study show that the accuracy and reliability of estimates is affected by rater and assessment methods used, and these can affect the mean estimates and the outcomes of means comparisons (additional previous reports have indicated the potential effects of rating methods in hypothesis testing; 3,9,44). Many studies in plant pathology rely on plant disease severity assessment. Thus, it is important that estimates of severity be as accurate as is practically possible given the constraints of the assessment task $(6,32)$. Wherever possible, the percent ( 0 to $100 \%$ ) ratio scale should be used, raters should be trained, and, if possible, SADs should be used as assessment aids.

\section{Acknowledgments}

We thank the Administration des Services Techniques de l'Agriculture of the Grand Duchy of Luxembourg for funding this research through the successive SINTAMA and MACRY projects; H. Maraite (Catholic University of Louvain), B. Tychon (Université de Liegé), and L. Hoffmann (Centre de Recherche Public - Gabriel Lippmann) for their advice and suggestions; and G. Reiland, A. Mahtour, V. Schyns, B. Martin, C. Vrancken, G. Mirgain, M. Kails, and A. Nuttens for their technical support.

\section{Literature Cited}

1. Bardsley, S. J., and Ngugi, H. K. 2013. Reliability and accuracy of visual methods to quantify severity of foliar bacterial spot symptoms on peach and nectarine. Plant Pathol. 62:460-474.

2. Berger, R. D. 1980. Measuring disease intensity. Pages 28-31 in: Proc. E. C. Stakman Commemorative Symp. Crop Loss Assessment. Univ. Minn. Misc. Publ. 7, St. Paul

3. Bock, C. H., Gottwald, T. R., Parker, P. E., Ferrandino, F., Welham, S., van den Bosch, F., and Parnell, S. 2010. Some consequences of using the Horsfall-Barratt scale for hypothesis testing. Phytopathology 100:1030-1041.

4. Bock, C. H., Parker, P. E., Cook, A. Z., and Gottwald, T. R. 2008. Characteristics of the perception of different severity measures of citrus canker and the relationships between the various symptom types. Plant Dis. 92:927-939.

5. Bock, C. H., Parker, P. E., Cook, A. Z., and Gottwald, T. R. 2008. Visual rating and the use of image analysis for assessing different symptoms of Citrus canker on grapefruit leaves. Plant Dis. 92:530-541.

6. Bock, C. H., Poole, G. H., Parker, P. E., and Gottwald, T. R. 2010. Plant disease severity estimated visually, by digital photography and image analysis, and by hyperspectral imaging. Crit. Rev. Plant Sci. 29:59-107.

7. Bock, C. H., Wood, B. W., Van Den Bosch, F., Parnell, S., and Gottwald, T. R. 2013. The effect of Horsfall-Barratt category size on the accuracy and reliability of estimates of pecan scab severity. Plant Dis. 97:797-806.

8. Burdon, J. J., Thrall, P. H., and Ericson, L. 2006. The current and future dynamics of disease in plant communities. Annu. Rev. Phytopathol. 44: 19-39.

9. Chiang, K. S., Liu, S. H., Bock, C. H., and Gottwald, T. R. 2014. What interval characteristics make a good disease assessment category scale? Phytopathology 104:575-585.

10. Christ, B. J. 1991. Effect of disease assessment method on ranking potato cultivars for resistance to early blight. Plant Dis. 75:353-356.

11. Cooke, B. M.2006. Disease assessment and yield loss. Pages 43-80 in: The Epidemiology of Plant Diseases. B. M. Cooke, D. G. Jones, and B. Kaye, eds. Springer, The Netherlands.

12. Dixon, G. R., and Doodson, J. K. 1971. Assessment keys for some diseases of vegetable, fodder, and forage crops. J. Nat. Inst. Agric. Bot. 23:299-307.

13. El Jarroudi, M., Delfosse, P., Maraite, H., Hoffmann, L., and Tychon, B. 2009. Assessing the accuracy of simulation model for Septoria leaf blotch disease progress on winter wheat. Plant Dis. 93:983-992.

14. El Jarroudi, M., Kouadio, A. L., Mackels, C., Tychon, B., Delfosse, P., and Bock, C. H. A comparison between visual estimates and image analysis measurements to determine Septoria leaf blotch severity in winter wheat. Plant Pathol. In press.

15. Gaunt, R. E. 1995. The relationship between plant disease severity and yield. Annu. Rev. Phytopathol. 33:119-144.

16. Hock, J., Kranz, J., and Renfro, B. L. 1992. Tests of standard diagrams for field use in assessing the tarspot disease complex of maize (Zea mays). Trop. Pest Manage. 38:314-318
17. Horsfall, J. G., and Barratt, R. W. 1945. An improved grading system for measuring plant disease. (Abstr.) Phytopathology 35:655.

18. James, C. A. 1971. A Manual of Assessment Keys for Plant Diseases. American Phytopathological Society, St. Paul, MN.

19. James, W. C. 1971. An illustrated series of assessment keys for plant diseases, their preparation and usage. Can. Plant Dis. Surv. 51:39-65.

20. James, W. C. 1974. Assessment of plant diseases and losses. Annu. Rev. Phytopathol. 12:27-48.

21. Kranz, J. 1977. A study on maximum severity in plant disease. Pages 169-173 in: Travaux dédiés à G. Viennot-Bourgin, Société Française de Phytopathologie, Paris, France.

22. Kranz, J.1988. Measuring plant disease. Pages 35-50 in: Experimental Techniques in Plant Disease Epidemiology. J. Kranz and J. Rotem, eds. Springer, Berlin, Heidelberg.

23. Lamari, L. 2002. Assess: Image Analysis Software for Plant Disease Quantification. American Phytopathological Society, St. Paul, MN.

24. Lin, L. I. 1989. A concordance correlation coefficient to evaluate reproducibility. Biometrics 45:255-268.

25. Lindow, S. E., and Webb, R. R. 1983. Quantification of foliar plant disease symptoms by microcomputer-digitized video image analysis. Phytopathology 73:520-524.

26. Lu, L., and Shara, N.2007. Reliability analysis: Calculate and compare intraclass correlation coefficients (ICC) in SAS. Statistics and Data Analysis. NeSug 2007. Online publication. http://www.nesug.org/Proceedings/nesug07/ sa/sa13.pdf.

27. Madden, L. V., Hughes, G., and Van Den Bosch, F. 2007. The Study of Plant Disease Epidemics. American Phytopathological Society, St. Paul, MN.

28. Martin, D. P., and Rybicki, E. P. 1998. Microcomputer-based quantification of maize streak virus symptoms in Zea mays. Phytopathology 88:422-427.

29. Moya, E. A., Barrales, L. R., and Apablaza, G. E. 2005. Assessment of the disease severity of squash powdery mildew through visual analysis, digital image analysis and validation of these methodologies. Crop Prot. 24:785-789.

30. Nilsson, H.-E. 1995. Remote sensing and image analysis in plant pathology. Annu. Rev. Phytopathol. 33:489-527.

31. Nita, M., Ellis, M. A., and Madden, L. V. 2003. Reliability and accuracy of visual estimation of Phomopsis leaf blight of strawberry. Phytopathology 93:995-1005.

32. Nutter, F. W., Jr., and Esker, P. D. 2006. The role of psychophysics in phytopathology: The Weber-Fechner law revisited. Eur. J. Plant Pathol. 114:199-213.

33. Nutter, F. W., Jr., and Gaunt, R. E. 1996. Recent developments in methods for assessing disease losses in forage/pasture crop. Pages 93-118 in: Pasture and Forage Crop Pathology. S. Chakraborty, D. T. Leath, R. A. Skipp, G. A Pederson, R. Bray, G. C. M. Latch, and F. W. Nutter, eds. American Society of Agronomy, Crop Science Society of America, and Soil Science Society of America, Madison, WI.

34. Nutter, F. W., Jr., Gleason, M. L., Jenco, J. H., and Christians, N. L. 1993 Accuracy, intrarater repeatability, and interrater reliability of disease assessment systems. Phytopathology 83:806-812.

35. Nutter, F. W., Jr., and Schultz, P. M. 1995. Improving the accuracy and precision of disease assessments: Selection of methods and use of computeraided training programs. Can. J. Plant Pathol. 17:174-184.

36. Nutter, F. W., Jr., Teng, P. S., and Shokes, F. M. 1991. Disease assessment terms and concepts. Plant Dis. 75:1187-1188.

37. Nutter, F. W., Jr., and Worawitlikit, O. 1989. Disease.Pro: A computerized program for evaluating and improving a persons ability to assess disease proportion. (Abstr.) Phytopathology 79:1135.

38. Parker, S. R., Shaw, M. W., and Royle, D. J. 1995. The reliability of visual estimates of disease severity on cereal leaves. Plant Pathol. 44:856-864.

39. Price, T. V., and Osborne, C. F. 1990. Computer imaging and its application to some problems in agriculture and plant science. Crit. Rev. Plant Sci. 9 235-266.

40. Sherwood, R. J., Berg, C. C., Hoover, M. R., and Zeiders, K. E. 1983. Illusions in visual assessment of Stagonospora leafspot of orchard grass. Phytopathology 73:173-177

41. Steddom, K., Jones, D., Rudd, J., and Rush, C. M. 2005. Analysis of field plot images with segmentation analysis, effect of glare and shadows. (Abstr.) Phytopathology 95:S99.

42. Steddom, K., McMullen, M., Schatz, B., and Rush, C.M. 2005. Comparing image format and resolution for assessment of foliar diseases of wheat Online publication. Plant Health Prog.

43. Stonehouse, J. 1994. Assessment of Andean bean diseases using visual keys Plant Pathol. 43:519-527.

44. Todd, L. A., and Kommedahl, T. 1994. Image analysis and visual estimates for evaluating disease reactions of corn to Fusarium stalk rot. Plant Dis. 78:876-878

45. Tomerlin, J. R., and Howell, A. 1988. Distrain: A computer program for training people to estimate disease severity on cereal leaves. Plant Dis. 72:455-459.

46. Yadav, N. V. S., De Vos, S. M., Bock, C. H., and Wood, B. W. 2013. Development and validation of standard area diagrams to aid assessment of pecan scab symptoms on fruit. Plant Pathol. 62:325-335.

47. Zadoks, J. C., Chang, T. T., and Konzak, C. F. 1974. A decimal code for the growth stages of cereals. Weed Res. 14:415-421. 